\title{
Ciric-type $\delta$-contractions in metric spaces endowed with a graph
}

\author{
Cristian Chifu $^{1 *}$ and Adrian Petruşel ${ }^{2}$
}

${ }^{\text {*Correspondence: }}$

cristian.chifu@tbs.ubbcluj.ro

${ }^{1}$ Department of Business,

Babeş-Bolyai University

Cluj-Napoca, Horea street, 7,

Cluj-Napoca, 400174, Romania

Full list of author information is

available at the end of the article

\begin{abstract}
The purpose of this paper is to present some fixed-point and strict fixed-point results in a metric space endowed with a graph, using a contractive condition of Ćirić type with respect to the functional $\delta$. The data dependence of the fixed-point set, the well-posedness of the fixed-point problem, and the limit shadowing property are also studied.
\end{abstract}

MSC: $47 \mathrm{H} 10 ; 54 \mathrm{H} 25$

Keywords: fixed point; strict fixed point; metric space; connected graph; well-posed problem; limit shadowing property

\section{Preliminaries}

A recent research direction in fixed-point theory is the study of the fixed-point problem for single-valued and multivalued operators in the context of a metric space endowed with a graph. This approach was recently considered by Jachymski in [1], Gwóźdź-Lukawska and Jachymski in [2], and then it was developed in many other papers ([3-5], etc.).

On the other hand, fixed points and strict fixed points (also called end-points) are important elements in mathematical economics and game theory. It represents optimal preferences in some Arrow-Debreu type models or Nash type equilibrium points for some abstract noncooperative games, see, for example, [6] and [7]. From this perspective, it is important to give fixed and strict fixed-point theorems for multivalued operators.

We shall begin by presenting some notions and notations that will be used throughout the paper.

Let $(X, d)$ be a metric space and $\Delta$ be the diagonal of $X \times X$. Let $G$ be a directed graph such that the set $V(G)$ of its vertices coincides with $X$ and $\Delta \subseteq E(G), E(G)$ being the set of the edges of the graph. Assuming that $G$ has no parallel edges, we will suppose that $G$ can be identified with the pair $(V(G), E(G))$.

If $x$ and $y$ are vertices of $G$, then a path in $G$ from $x$ to $y$ of length $k \in \mathbb{N}$ is a finite sequence $\left(x_{n}\right)_{n \in\{0,1,2, \ldots, k\}}$ of vertices such that $x_{0}=x, x_{k}=y$ and $\left(x_{i-1}, x_{i}\right) \in E(G)$, for $i \in\{1,2, \ldots, k\}$.

Let us denote by $\tilde{G}$ the undirected graph obtained from $G$ by ignoring the direction of edges. Notice that a graph $G$ is connected if there is a path between any two vertices and it is weakly connected if $\tilde{G}$ is connected.

Let us consider the following families of subsets of a metric space $(X, d)$ :

$$
\begin{aligned}
& P(X):=\{Y \in \mathcal{P}(X) \mid Y \neq \emptyset\}, \quad P_{b}(X):=\{Y \in P(X) \mid Y \text { is bounded }\}, \\
& P_{c l}(X):=\{Y \in P(X) \mid Y \text { is closed }\}, \quad P_{c p}(X):=\{Y \in P(X) \mid Y \text { is compact }\} .
\end{aligned}
$$

O2014 Chifu and Petrusel; licensee Springer. This is an Open Access article distributed under the terms of the Creative Commons Attribution License (http://creativecommons.org/licenses/by/2.0), which permits unrestricted use, distribution, and reproduction in any medium, provided the original work is properly cited. 
Let us define the gap functional between the sets $A$ and $B$ in the metric space $(X, d)$ as:

$$
D: P(X) \times P(X) \rightarrow \mathbb{R}_{+} \cup\{+\infty\}, \quad D(A, B)=\inf \{d(a, b) \mid a \in A, b \in B\}
$$

and the (generalized) Pompeiu-Hausdorff functional as

$$
\begin{aligned}
& H: P(X) \times P(X) \rightarrow \mathbb{R}_{+} \cup\{+\infty\}, \\
& H(A, B)=\max \left\{\sup _{a \in A} D(a, B), \sup _{b \in B} D(A, b)\right\} .
\end{aligned}
$$

The generalized diameter functional is denoted by $\delta: P(X) \times P(X) \rightarrow \mathbb{R}_{+} \cup\{\infty\}$, and defined by

$$
\delta(A, B)=\sup \{d(a, b) \mid a \in A, b \in B\} .
$$

Denote by $\operatorname{diam}(A):=\delta(A, A)$ the diameter of the set $A$.

Let $T: X \rightarrow P(X)$ be a multivalued operator and Graphic $(T):=\{(x, y) \mid y \in T(x)\}$ the graphic of T. $x \in X$ is called fixed point for $T$ if and only if $x \in T(x)$, and it is called strict fixed point if and only if $\{x\}=T(x)$.

The set $\operatorname{Fix}(T):=\{x \in X \mid x \in T(x)\}$ is called the fixed-point set of $T$, while $S \operatorname{Fix}(T)=$ $\{x \in X \mid\{x\}=T(x)\}$ is called the strict fixed-point set of $T$. Notice that $S \operatorname{Fix}(T) \subseteq \operatorname{Fix}(T)$.

We will write $E(G) \in I(T \times T)$ if and only if for every $x, y \in X$ with $(x, y) \in E(G)$ we have $T(x) \times T(y) \subset E(G)$.

For the particular case of a single-valued operator $t: X \rightarrow X$ the above notations should be considered accordingly. In particular, the condition $E(G) \in I(t \times t)$ means that the operator $t$ is edge preserving (in the sense of the Jachymski's definition of a Banach contraction), i.e. for each $x, y \in X$ with $(x, y) \in E(G)$ we have $(t(x), t(y)) \in E(G)$ (see [1]). We will also denote by $O\left(x_{0}, n\right):=\left\{x_{0}, t\left(x_{0}\right), t^{2}\left(x_{0}\right), \ldots, t^{n}\left(x_{0}\right)\right\}$ the orbit of order $n$ of the operator $t$ corresponding to $x_{0} \in X$.

In this paper we prove some fixed-point and strict fixed-point theorems for singlevalued and multivalued operators satisfying a contractive condition of Cirić type with respect to the functional $\delta$. Our results also generalize and extend some fixed-point theorems in partially ordered complete metric spaces given in Harjani, Sadarangani [8], Nieto, Rodríguez-López [9] and [10], Nieto et al. [11], O’Regan, Petruşel [12], Petruşel, Rus [13] and Ran, Reurings [14]. For other general results concerning Ćirić type fixed-point theorems see Rus [15].

In the main section of the paper we give results concerning the existence and uniqueness of the fixed point and of the strict fixed point of a Cirić type (single-valued and multivalued) contraction. Then the well-posedness of the fixed-point problem, the data dependence of the fixed-point set, and the limit shadowing property are also studied. Our results complement and extend some recent theorems given in [16] for multivalued Reich-type operators.

\section{Main results}

In this section we present the main results of the paper concerning the fixed-point problem and, respectively, the strict fixed-point problem for a single-valued, respectively, of a multivalued Ćirić type contraction. 
Definition 2.1 Let $(X, d)$ be a metric space and $T: X \rightarrow P_{c l}(X)$ be a multivalued operator. By definition, the fixed-point problem is well-posed for $T$ with respect to $H$ if:

(i) $S$ Fix $T=\left\{x^{*}\right\}$;

(ii) If $\left(x_{n}\right)_{n \in \mathbb{N}}$ is a sequence in $X$ such that $H\left(x_{n}, T\left(x_{n}\right)\right) \rightarrow 0$, as $n \rightarrow \infty$, then $x_{n} \stackrel{d}{\rightarrow} x^{*}$, as $n \rightarrow \infty$.

Definition 2.2 Let $(X, d)$ be a metric space and $T: X \rightarrow P(X)$ be a multivalued operator. By definition $T$ has the limit shadowing property if for any sequence $\left(y_{n}\right)_{n \in \mathbb{N}}$ from $X$ such that $D\left(y_{n+1}, T\left(y_{n}\right)\right) \rightarrow 0$, as $n \rightarrow \infty$, there exists $\left(x_{n}\right)_{n \in \mathbb{N}}$, a sequence of successive approximation of $T$, such that $d\left(x_{n}, y_{n}\right) \rightarrow 0$, as $n \rightarrow \infty$.

In order to prove the limit shadowing property we shall need Cauchy's lemma.

Lemma 2.1 (Cauchy's lemma) Let $\left(a_{n}\right)_{n \in \mathbb{N}}$ and $\left(b_{n}\right)_{n \in \mathbb{N}}$ be two sequences of non-negative real numbers, such that $\sum_{k=0}^{+\infty} a_{k}<+\infty$ and $b_{n} \rightarrow 0$, as $n \rightarrow \infty$. Then

$$
\sum_{k=0}^{n} a_{n-k} b_{k} \rightarrow 0, \quad \text { as } n \rightarrow \infty
$$

The first main result of this paper is the following result for the case of single-valued operators. The proof of this result is inspired by the proof of Ćirić's fixed-point theorem in [17] and the approach introduced for metric spaces endowed with a graph by Jachymski in [1].

Theorem 2.1 Let $(X, d)$ be a complete metric space and $G$ be a directed graph such that the triple $(X, d, G)$ satisfies the following property:

$(P)$

$$
\begin{aligned}
& \text { for any sequence }\left(x_{n}\right)_{n \in \mathbb{N}} \subset X \text { with } x_{n} \rightarrow x \text { as } n \rightarrow \infty \text {, there exists a subsequence } \\
& \left(x_{k_{n}}\right)_{n \in \mathbb{N}} \text { of }\left(x_{n}\right)_{n \in \mathbb{N}} \text { such that }\left(x_{k_{n}}, x\right) \in E(G) .
\end{aligned}
$$

Let $t: X \rightarrow X$ be a single-valued operator. Suppose the following assertions hold:

(i) there exists $a \in[0,1[$ such that

$$
d(t(x), t(y)) \leq a \cdot \max \{d(x, y), d(x, t(x)), d(y, t(y)), d(x, t(y)), d(y, t(x))\},
$$

for all $(x, y) \in E(G)$;

(ii) there exists $x_{0} \in X$ such that $\left(x_{0}, t\left(x_{0}\right)\right) \in E(G)$;

(iii) $E(G) \in I(t \times t)$;

(iv) if $(x, y) \in E(G)$ and $(y, z) \in E(G)$, then $(x, z) \in E(G)$.

In these conditions we have:

(a) (existence) $\operatorname{Fix}(t) \neq \emptyset$;

(b) (uniqueness) If, in addition, the following implication holds

$$
x^{*}, y^{*} \in \operatorname{Fix}(t) \quad \Rightarrow \quad\left(x^{*}, y^{*}\right) \in E(G),
$$

then $\operatorname{Fix}(t)=\left\{x^{*}\right\}$. 
Proof (a) Let $x_{0} \in X$ such that $\left(x_{0}, t\left(x_{0}\right)\right) \in E(G)$. By (iii) we obtain $\left(t^{i}\left(x_{0}\right), t^{i+1}\left(x_{0}\right)\right) \in E(G)$, for all $i \in \mathbb{N}$. Then, by (iv), we get

$$
\left(t^{i}\left(x_{0}\right), t^{j}\left(x_{0}\right)\right) \in E(G), \quad \text { for all } i, j \in \mathbb{N} \text { with } i<j .
$$

Since $\Delta \subset E(G)$ we get

$$
\left(t^{i}\left(x_{0}\right), t^{j}\left(x_{0}\right)\right) \in E(G), \quad \text { for all } i, j \in \mathbb{N} \text { with } i \leq j .
$$

For $n \in \mathbb{N}^{*}$, let $i, j \in \mathbb{N}$ with $1 \leq i<j \leq n$. Then

$$
d\left(t^{i}\left(x_{0}\right), t^{j}\left(x_{0}\right)\right) \leq a \operatorname{diam}\left(O\left(x_{0} ; n\right)\right)
$$

Notice now that, from the above relation, it follows that there exists $k \in \mathbb{N}^{*}$ with $k \leq n$ such that

$$
d\left(x_{0}, t^{k}\left(x_{0}\right)\right)=\operatorname{diam}\left(O\left(x_{0} ; n\right)\right)
$$

In order to show that the sequence $\left(t^{n}\left(x_{0}\right)\right)_{n \in \mathbb{N}}$ is Cauchy, let us consider $n, m \in \mathbb{N}$ with $n<m$. Then we have

$$
d\left(t^{n}\left(x_{0}\right), t^{m}\left(x_{0}\right)\right) \leq a \operatorname{diam}\left(O\left(t^{n-1}\left(x_{0}\right) ; m-n+1\right)\right) .
$$

By (2.2) there exists $p \in \mathbb{N}$ with $p \leq m-n+1$ such that

$$
\operatorname{diam}\left(O\left(t^{n-1}\left(x_{0}\right) ; m-n+1\right)\right)=d\left(t^{n-1}\left(x_{0}\right), t^{p}\left(t^{n-1}\left(x_{0}\right)\right)\right) .
$$

Then

$$
\begin{aligned}
d\left(t^{n-1}\left(x_{0}\right), t^{p}\left(t^{n-1}\left(x_{0}\right)\right)\right) & =d\left(t^{n-1}\left(x_{0}\right), t^{p+n-1}\left(x_{0}\right)\right)=d\left(t\left(t^{n-2}\left(x_{0}\right)\right), t^{p+1}\left(t^{n-2}\left(x_{0}\right)\right)\right) \\
& \leq a \operatorname{diam}\left(O\left(t^{n-2}\left(x_{0}\right) ; p+1\right)\right) \\
& \leq a \operatorname{diam}\left(O\left(t^{n-2}\left(x_{0}\right) ; m-n+2\right)\right) .
\end{aligned}
$$

Thus, we get

$$
\begin{aligned}
\operatorname{diam}\left(O\left(t^{n-1}\left(x_{0}\right) ; m-n+1\right)\right) & \leq a \operatorname{diam}\left(O\left(t^{n-2}\left(x_{0}\right) ; m-n+2\right)\right) \leq \cdots \\
& \leq a^{n} \operatorname{diam}\left(O\left(x_{0} ; m\right)\right)
\end{aligned}
$$

Hence

$$
d\left(t^{n}\left(x_{0}\right), t^{m}\left(x_{0}\right)\right) \leq a^{n} \operatorname{diam}\left(O\left(x_{0} ; m\right)\right)
$$

Notice now that

$$
\operatorname{diam}\left(O\left(x_{0} ; m\right)\right) \leq \frac{1}{1-a} d\left(x_{0}, t\left(x_{0}\right)\right), \quad \text { for all } m \in \mathbb{N}
$$


Indeed, if we take $m \in \mathbb{N}$ arbitrary, then by (2.2), there exists $r \in \mathbb{N}$ such that $1 \leq r \leq m$ and $d\left(x_{0}, t^{r}\left(x_{0}\right)\right)=\operatorname{diam}\left(O\left(x_{0} ; m\right)\right)$. Then, using $(2.1)$, we get

$$
\begin{aligned}
d\left(x_{0}, t^{r}\left(x_{0}\right)\right) & \leq d\left(x_{0}, t\left(x_{0}\right)\right)+d\left(t\left(x_{0}\right), t^{r}\left(x_{0}\right)\right) \leq d\left(x_{0}, t\left(x_{0}\right)\right)+a \operatorname{diam}\left(O\left(x_{0} ; m\right)\right) \\
& =d\left(x_{0}, t\left(x_{0}\right)\right)+a d\left(x_{0}, t^{r}\left(x_{0}\right)\right) .
\end{aligned}
$$

Hence we have

$$
\operatorname{diam}\left(O\left(x_{0} ; m\right)\right)=d\left(x_{0}, t^{r}\left(x_{0}\right)\right) \leq \frac{1}{1-a} d\left(x_{0}, t\left(x_{0}\right)\right),
$$

proving (2.3). Now, we can conclude that

$$
d\left(t^{n}\left(x_{0}\right), t^{m}\left(x_{0}\right)\right) \leq \frac{a^{n}}{1-a} d\left(x_{0}, t\left(x_{0}\right)\right), \quad \text { for all } n, m \in \mathbb{N} \text { with } n<m .
$$

Thus, (2.4) shows that the sequence $\left(t^{n}\left(x_{0}\right)\right)_{n \in \mathbb{N}}$ is Cauchy and, as a consequence of the completeness of the space, it converges to an element $x^{*} \in X$.

We will show now that $x^{*} \in \operatorname{Fix}(t)$.

Notice first that, by the property $(P)$, there exists a subsequence $\left(x_{k_{n}}\right)_{n \in \mathbb{N}}$ of $\left(x_{n}\right)_{n \in \mathbb{N}}$ such that $\left(x_{k_{n}}, x^{*}\right) \in E(G)$ for each $n \in \mathbb{N}$. Now, we can write

$$
\begin{aligned}
& d\left(x^{*}, t\left(x^{*}\right)\right) \\
& \leq d\left(x^{*}, x_{k_{n+1}}\right)+d\left(t\left(x_{k_{n}}\right), t\left(x^{*}\right)\right) \\
& \leq d\left(x^{*}, x_{k_{n+1}}\right) \\
&+a \max \left\{d\left(x_{k_{n}}, x^{*}\right), d\left(x_{k_{n}}, t\left(x_{k_{n}}\right)\right), d\left(x^{*}, t\left(x^{*}\right)\right), d\left(x_{k_{n}}, t\left(x^{*}\right)\right), d\left(x^{*}, t\left(x_{k_{n}}\right)\right)\right\} \\
& \leq d\left(x^{*}, x_{k_{n+1}}\right)+a\left(d\left(x_{k_{n}}, x^{*}\right)+d\left(x_{k_{n}}, t\left(x_{k_{n}}\right)\right)+d\left(x^{*}, t\left(x^{*}\right)\right)+d\left(x^{*}, t\left(x_{k_{n}}\right)\right)\right) .
\end{aligned}
$$

Hence

$$
d\left(x^{*}, t\left(x^{*}\right)\right) \leq \frac{1}{1-a}\left[(1+a) d\left(x^{*}, x_{k_{n+1}}\right)+a d\left(x_{k_{n}}, x^{*}\right)+a d\left(x_{k_{n}}, x_{k_{n+1}}\right)\right] .
$$

Letting $n \rightarrow+\infty$ we get $x^{*} \in \operatorname{Fix}(t)$.

(b) Suppose that there exist $x^{*}, y^{*} \in \operatorname{Fix}(t)$ with $x^{*} \neq y^{*}$.

Using (i) and the additional hypothesis of (b), we obtain

$$
\begin{aligned}
d\left(x^{*}, y^{*}\right) & =d\left(t\left(x^{*}\right), t\left(y^{*}\right)\right) \\
& \leq a \max \left\{d\left(x^{*}, y^{*}\right), d\left(x^{*}, t\left(x^{*}\right)\right), d\left(t\left(y^{*}\right), y^{*}\right), d\left(x^{*}, t\left(y^{*}\right)\right), d\left(y^{*}, t\left(x^{*}\right)\right)\right\} \\
& =a d\left(x^{*}, y^{*}\right),
\end{aligned}
$$

which is a contradiction.

Remark 2.1 Notice that, from the proof of the above theorem, it follows that the sequence $\left(t^{n}\left(x_{0}\right)\right)_{n \in \mathbb{N}}$ converges to $x^{*}$ in $(X, d)$. 
Remark 2.2 If in the above theorem, instead of property $(P)$ we suppose that $t$ has closed graphic, then we can reach the same conclusion. Moreover if we suppose that

$$
x^{*}, y^{*} \in \operatorname{Fix}(t) \quad \Rightarrow \quad\left(x^{*}, y^{*}\right) \in E(G),
$$

then we get again $\operatorname{Fix}(t)=\left\{x^{*}\right\}$.

Based on the above theorem, we can prove now our second main result.

Theorem 2.2 Let $(X, d)$ be a complete metric space and $G$ be a directed graph such that the triple $(X, d, G)$ satisfies the following property:

(P)

$$
\begin{aligned}
& \text { for any sequence }\left(x_{n}\right)_{n \in \mathbb{N}} \subset X \text { with } x_{n} \rightarrow x \text { as } n \rightarrow \infty \text {, there exists a subsequence } \\
& \left(x_{k_{n}}\right)_{n \in \mathbb{N}} \text { of }\left(x_{n}\right)_{n \in \mathbb{N}} \text { such that }\left(x_{k_{n}}, x\right) \in E(G) .
\end{aligned}
$$

Let $T: X \rightarrow P_{b}(X)$ be a multivalued operator. Suppose the following assertions hold:

(i) there exists $a \in[0,1[$ such that

$$
\delta(T(x), T(y)) \leq a \cdot \max \{d(x, y), \delta(x, T(x)), \delta(y, T(y)), D(x, T(y)), D(y, T(x))\}
$$

for all $(x, y) \in E(G)$;

(ii) there exists $x_{0} \in X$ such that, for all $y \in T\left(x_{0}\right)$, we have $\left(x_{0}, y\right) \in E(G)$;

(iii) $E(G) \in I(T \times T)$;

(iv) if $(x, y) \in E(G)$ and $(y, z) \in E(G)$, then $(x, z) \in E(G)$.

In these conditions we have:

(a) (existence) $\operatorname{Fix}(T)=S \operatorname{Fix}(T) \neq \emptyset$;

(b) (uniqueness) If, in addition, the following implication holds:

$$
x^{*}, y^{*} \in \operatorname{Fix}(T) \quad \Rightarrow \quad\left(x^{*}, y^{*}\right) \in E(G),
$$

then $\operatorname{Fix}(T)=S \operatorname{Fix}(T)=\left\{x^{*}\right\}$;

(c) (well-posedness of the fixed-point problem) If $T$ has closed graphic and for any sequence $\left(x_{n}\right)_{n \in \mathbb{N}}, x_{n} \in X$ with $H\left(x_{n}, T\left(x_{n}\right)\right) \rightarrow 0$, as $n \rightarrow \infty$, we have $\left(x_{n}, x^{*}\right) \in E(G)$, then the fixed-point problem is well-posed for $T$ with respect to $H$;

(d) (limit shadowing property of T) If $a<\frac{1}{3}$ and $\left(y_{n}\right)_{n \in \mathbb{N}}$ is a sequence in $X$ such that the following implication holds:

$$
D\left(y_{n+1}, T\left(y_{n}\right)\right) \rightarrow 0, \quad \text { as } n \rightarrow \infty \quad \Rightarrow \quad\left(y_{n}, x^{*}\right) \in E(G), \quad \forall n \in \mathbb{N} \text {, }
$$

then $T$ has the limit shadowing property.

Proof (a) Let $0<q<1$ be an arbitrary real number. Notice first that, for any $x \in X$, there exists $u \in T(x)$ such that $a^{q} \delta(x, T(x)) \leq d(x, u)$. In this way, we get an operator $t: X \rightarrow X$ which assigns to each $x \in X$ the element $t(x) \in T(x)$ with

$$
a^{q} \delta(x, T(x)) \leq d(x, t(x))
$$


Then, for $(x, y) \in E(G)$, we have

$$
\begin{aligned}
& d(t(x), t(y)) \\
& \quad \leq \delta(T(x), T(y)) \\
& \quad \leq a a^{-q} \max \left\{a^{q} d(x, y), a^{q} \delta(x, T(x)), a^{q} \delta(y, T(y)), a^{q} D(x, T(y)), a^{q} D(y, T(x))\right\} \\
& \quad \leq a^{1-q} \max \{d(x, y), d(x, t(x)), d(y, t(y)), d(x, t(y)), d(y, t(x))\} .
\end{aligned}
$$

Thus, the operator $t$ satisfies all the hypotheses of Theorem 2.1 and, as a consequence, it has a fixed point $x^{*} \in X$. Then $x^{*} \in \operatorname{Fix}(T)$. If we suppose now that there exists $x \in \operatorname{Fix}(T) \backslash S \operatorname{Fix}(T)$, then, since $(x, x) \in \Delta$, from the condition (i) (with $y=x$ ), we get $\delta(T(x)) \leq a \delta(T(x))$, which implies (since $a<1$ ) that $\delta(T(x))=0$. Thus $T(x)=\{x\}$. This is a contradiction with $x \in \operatorname{Fix}(T) \backslash S \operatorname{Fix}(T)$, proving that $\operatorname{Fix}(T)=S \operatorname{Fix}(T) \neq \emptyset$.

(b) Suppose that there exist $x^{*}, y^{*} \in \operatorname{Fix}(T)=S \operatorname{Fix}(T)$.

Using (i) we obtain

$$
\begin{aligned}
d\left(x^{*}, y^{*}\right) & =\delta\left(T\left(x^{*}\right), T\left(y^{*}\right)\right) \\
& \leq a \cdot \max \left\{d\left(x^{*}, y^{*}\right), \delta\left(x^{*}, T\left(x^{*}\right)\right), \delta\left(y^{*}, T\left(y^{*}\right)\right), D\left(x^{*}, T\left(y^{*}\right)\right), D\left(y^{*}, T\left(x^{*}\right)\right)\right\} \\
& =a d\left(x^{*}, y^{*}\right),
\end{aligned}
$$

which implies that $d\left(x^{*}, y^{*}\right)=0$. Hence $\operatorname{Fix}(T)=S \operatorname{Fix}(T)=\left\{x^{*}\right\}$.

(c) Let $\left(x_{n}\right)_{n \in \mathbb{N}}, x_{n} \in X$, be a sequence with the property that $H\left(x_{n}, T\left(x_{n}\right)\right) \rightarrow 0$, as $n \rightarrow \infty$. It is obvious that $H\left(x_{n}, T\left(x_{n}\right)\right)=\delta\left(x_{n}, T\left(x_{n}\right)\right)$.

Let $x^{*} \in \operatorname{Fix}(T)=S \operatorname{Fix}(T)$. Then

$$
\begin{aligned}
d\left(x_{n}, x^{*}\right) & =\delta\left(x_{n}, T\left(x^{*}\right)\right) \leq \delta\left(x_{n}, T\left(x_{n}\right)\right)+\delta\left(T\left(x_{n}\right), T\left(x^{*}\right)\right) \\
& \leq \delta\left(x_{n}, T\left(x_{n}\right)\right)+a \cdot \max \left\{d\left(x_{n}, x^{*}\right), \delta\left(x_{n}, T\left(x_{n}\right)\right), d\left(x_{n}, x^{*}\right), D\left(x^{*}, T\left(x_{n}\right)\right)\right\} \\
& \leq \delta\left(x_{n}, T\left(x_{n}\right)\right)+a \delta\left(x_{n}, T\left(x_{n}\right)\right)+a d\left(x_{n}, x^{*}\right) .
\end{aligned}
$$

Hence

$$
d\left(x_{n}, x^{*}\right) \leq \frac{1+a}{1-a} \delta\left(x_{n}, T\left(x_{n}\right)\right) \rightarrow 0, \quad \text { as } n \rightarrow+\infty,
$$

and, as a consequence, the fixed-point problem is well-posed for $T$ with respect to $H$.

(d) Let $\left(y_{n}\right)_{n \in \mathbb{N}}$ be a sequence in $X$ such that $D\left(y_{n+1}, T\left(y_{n}\right)\right) \rightarrow 0$, as $n \rightarrow \infty$ and let $\left(x_{n}\right)_{n \in \mathbb{N}}$ be a sequence of successive approximation of $T$ starting from $x_{0} \in X$, constructed as in the proof of Theorem 2.1. We shall prove that $d\left(x_{n}, y_{n}\right) \rightarrow 0$, as $n \rightarrow \infty$.

Let $x^{*} \in \operatorname{Fix}(T)=S \operatorname{Fix}(T)$. Then

$$
d\left(x_{n}, y_{n}\right) \leq d\left(x_{n}, x^{*}\right)+d\left(x^{*}, y_{n}\right)
$$

In what follows we shall prove that $d\left(x^{*}, y_{n}\right) \rightarrow 0$, as $n \rightarrow \infty$. Then we have

$$
\begin{aligned}
d\left(x^{*}, y_{n+1}\right) & \leq \delta\left(x^{*}, T\left(y_{n}\right)\right)+D\left(y_{n+1}, T\left(y_{n}\right)\right)=\delta\left(T\left(x^{*}\right), T\left(y_{n}\right)\right)+D\left(y_{n+1}, T\left(y_{n}\right)\right) \\
& \leq a \cdot \max \left\{d\left(x^{*}, y_{n}\right), \delta\left(y_{n}, T\left(y_{n}\right)\right), D\left(x^{*}, T\left(y_{n}\right)\right), d\left(y_{n}, x^{*}\right)\right\}+D\left(y_{n+1}, T\left(y_{n}\right)\right) \\
& \leq a \delta\left(y_{n}, T\left(y_{n}\right)\right)+a d\left(x^{*}, y_{n}\right)+D\left(y_{n+1}, T\left(y_{n}\right)\right) .
\end{aligned}
$$


Now, we can write

$$
\begin{aligned}
\delta\left(y_{n}, T\left(y_{n}\right)\right) & \leq d\left(x^{*}, y_{n}\right)+\delta\left(x^{*}, T\left(y_{n}\right)\right)=d\left(x^{*}, y_{n}\right)+\delta\left(T\left(x^{*}\right), T\left(y_{n}\right)\right) \\
& \leq d\left(x^{*}, y_{n}\right)+a \delta\left(y_{n}, T\left(y_{n}\right)\right)+a d\left(x^{*}, y_{n}\right) .
\end{aligned}
$$

Thus

$$
\delta\left(y_{n}, T\left(y_{n}\right)\right) \leq \frac{1+a}{1-a} d\left(x^{*}, y_{n}\right)
$$

If we replace this in the above relation, we get

$$
d\left(x^{*}, y_{n+1}\right) \leq \frac{2 a}{1-a} d\left(x^{*}, y_{n}\right)+D\left(y_{n+1}, T\left(y_{n}\right)\right)
$$

Hence

$$
\begin{aligned}
d\left(y_{n+1}, x^{*}\right) & \leq \frac{2 a}{1-a} d\left(y_{n}, x^{*}\right)+D\left(y_{n+1}, T\left(y_{n}\right)\right) \\
& \leq\left(\frac{2 a}{1-a}\right)^{2} d\left(y_{n-1}, x^{*}\right)+\frac{2 a}{1-a} D\left(y_{n}, T\left(y_{n-1}\right)\right)+D\left(y_{n+1}, T\left(y_{n}\right)\right) .
\end{aligned}
$$

Continuing this process we shall obtain

$$
d\left(y_{n+1}, x^{*}\right) \leq\left(\frac{2 a}{1-a}\right)^{n+1} d\left(y_{0}, x^{*}\right)+\sum_{k=0}^{n}\left(\frac{2 a}{1-a}\right)^{n-k} D\left(y_{k+1}, T\left(y_{k}\right)\right)
$$

If we consider $a_{n}=\left(\frac{2 a}{1-a}\right)^{n}$ and $b_{n}=D\left(y_{n+1}, T\left(y_{n}\right)\right)$ and using the fact that $a<\frac{1}{3}$, we obtain, via Cauchy's lemma, $d\left(x^{*}, y_{n}\right) \rightarrow 0$, as $n \rightarrow \infty$. Thus $d\left(x^{*}, y_{n}\right) \rightarrow 0$, as $n \rightarrow \infty$, and hence, the operator $T$ has the limit shadowing property.

Remark 2.3 If in Theorem 2.1, instead of property $(P)$, we suppose that every selection $t$ of $T$ has closed graphic, then we obtain $\operatorname{Fix}(T)=S \operatorname{Fix}(T) \neq \emptyset$. Moreover if we suppose that the following implication holds:

$$
x^{*}, y^{*} \in \operatorname{Fix}(T) \quad \Rightarrow \quad\left(x^{*}, y^{*}\right) \in E(G)
$$

then $\operatorname{Fix}(T)=S \operatorname{Fix}(T)=\left\{x^{*}\right\}$.

Proof Since every selection $t$ of $T$ has closed graphic, the conclusion follows by Theorem 2.1, via Remark 2.2.

Definition 2.3 Let $(X, d)$ be a metric space and $T: X \rightarrow P_{c l}(X)$ be a multivalued operator. By definition the fixed-point problem is well-posed in the generalized sense for $T$ with respect to $H$ if

(i) $S$ Fix $T \neq \emptyset$;

(ii) If $\left(x_{n}\right)_{n \in \mathbb{N}}$ is a sequence in $X$ such that $H\left(x_{n}, T\left(x_{n}\right)\right) \rightarrow 0$, as $n \rightarrow \infty$, then there exists a subsequence $\left(x_{k_{n}}\right)_{n \in \mathbb{N}}$ of $\left(x_{n}\right)_{n \in \mathbb{N}}$ such that $x_{k_{n}} \stackrel{d}{\rightarrow} x^{*}$, as $n \rightarrow \infty$. 
Remark 2.4 If in Theorem 2.1 instead of (c) we suppose the following assumption, (c'):

( $\mathrm{c}^{\prime}$ ) If every selection $t$ of $T$ has closed graphic and, in addition, we suppose that for any sequence $\left(x_{n}\right)_{n \in \mathbb{N}} \subset X$ with $H\left(x_{n}, T\left(x_{n}\right)\right) \rightarrow 0$, as $n \rightarrow \infty$, there exists a subsequence $\left(x_{k_{n}}\right)_{n \in \mathbb{N}}$ such that $\left(x_{k_{n}}, x^{*}\right) \in E(G)$ and $H\left(x_{k_{n}}, T\left(x_{k_{n}}\right)\right) \rightarrow 0$, then the fixed-point problem is well-posed in the generalized sense for $T$ with respect to $H$.

In what follows we shall present some examples of operators satisfying the hypotheses of our main results.

Example 2.1 Let $X=\{0,1\} \cup\left\{\frac{1}{2^{k}}: k \in \mathbb{N}^{*}\right\}$ and $f: X \rightarrow X$ given by

$$
f(x)= \begin{cases}x / 2, & \text { if } x \in\left\{\frac{1}{2^{k}}: k \in \mathbb{N}^{*}\right\} \\ 0, & \text { if } x \in\{0,1\}\end{cases}
$$

Let $V(G):=X$ and $E(G):=\{(0,1),(1,0)\} \cup\left\{\left(0, \frac{1}{2^{k}}\right),\left(\frac{1}{2^{k}}, 0\right),\left(1, \frac{1}{2^{k}}\right),\left(\frac{1}{2^{k}}, 1\right): k \in \mathbb{N}^{*}\right\} \cup \Delta$.

Then all the hypotheses of Theorem 2.1 are satisfied, Fix $(t)=\{0\}$ and, if we take $x_{0}=\frac{1}{2}$, then $\left(t^{n}\left(x_{0}\right)\right)_{n \in \mathbb{N}^{*}}$ converges to $x^{*}=0$.

Example 2.2 Let $X=\{(0,0),(0,1),(1,0)\}$ and $T: X \rightarrow P_{b}(X)$ given by

$$
T(x)=\left\{\begin{array}{l}
\{(0,0)\}, \quad x=(0,0), \\
\{(0,0),(1,0)\}, \quad x=(0,1), \\
\{(0,0)\}, \quad x=(1,0) .
\end{array}\right.
$$

Let $E(G):=\{((0,1) ;(1,0)),((1,0) ;(0,0))\} \cup \Delta$.

Notice that $\operatorname{Fix}(T)=S \operatorname{Fix}(T)=\{(0,0)\}$ and all the hypotheses in Theorem 2.2 are satisfied (the condition (i) is verified for $a \geq 0,71$ ).

Remark 2.5 It is also important to notice that, if we suppose that there exists $x \in \operatorname{Fix}(T) \backslash$ $S$ Fix $(T)$, then, since $(x, x) \in \Delta$, from the condition (i) in the above theorem (with $y=x$ ), we get $\delta(T(x)) \leq a \delta(T(x)$ ), which implies $\delta(T(x))=0$ (since $a<1$ ). This is a contradiction with $x \in \operatorname{Fix}(T) \backslash S \operatorname{Fix}(T)$, showing that we cannot get fixed points which are not strict fixed points in the presence of the condition (i) of the above theorem. It is an open problem to prove a similar theorem to the above one for a more general class of multivalued operators $T$.

The next result presents the data dependence of the fixed-point set of a multivalued operator which satisfies a contractive condition of Ćirić type.

Theorem 2.3 Let $(X, d)$ be a complete metric space and $G$ be a directed graph such that the triple $(X, d, G)$ satisfies property $(P)$. Let $T_{1}, T_{2}: X \rightarrow P_{b}(X)$ be two multivalued operators. Suppose the following assertions hold:

(i) for $i \in\{1,2\}$, there exist $a_{i} \in[0,1)$ such that

$$
\delta\left(T_{i}(x), T_{i}(y)\right) \leq a \cdot \max \left\{d(x, y), \delta\left(x, T_{i}(x)\right), \delta\left(y, T_{i}(y)\right), D\left(x, T_{i}(y)\right), D\left(y, T_{i}(x)\right)\right\}
$$

for all $(x, y) \in E(G)$; 
(ii) for each $x \in X$ and each $y \in T(x)$ we have $(x, y) \in E(G)$, for $i \in\{1,2\}$;

(iii) $E(G) \in I(T \times T)$;

(iv) if $(x, y) \in E(G)$ and $(y, z) \in E(G)$, then $(x, z) \in E(G)$;

(v) there exists $\eta>0$ such that $H\left(T_{1}(x), T_{2}(x)\right) \leq \eta$ for all $x \in X$.

Under these conditions we have:

(a) $\operatorname{Fix}\left(T_{i}\right)=S \operatorname{Fix}\left(T_{i}\right) \neq \emptyset, i \in\{1,2\}$;

(b) If, in addition, for $i \in\{1,2\}$, the following implication holds:

$$
x_{i}^{*}, y_{i}^{*} \in \operatorname{Fix}\left(T_{i}\right) \quad \Rightarrow \quad\left(x_{i}^{*}, y_{i}^{*}\right) \in E(G),
$$

then $\operatorname{Fix}\left(T_{i}\right)=S \operatorname{Fix}\left(T_{i}\right)=\left\{x_{i}^{*}\right\}$, for each $i \in\{1,2\}$;

(c) $H\left(S \operatorname{Fix}\left(T_{1}\right), S \operatorname{Fix}\left(T_{2}\right)\right) \leq \frac{\eta}{1-\max \left\{a_{1}, a_{2}\right\}}$.

Proof Conclusions (a) and (b) are immediate if we apply Theorem 2.2.

For (c) notice that we can prove that for every $x_{1}^{*} \in S \operatorname{Fix}\left(T_{1}\right)$, there exists $x_{2}^{*} \in S \operatorname{Fix}\left(T_{2}\right)$, such that

$$
d\left(x_{1}^{*}, x_{2}^{*}\right) \leq \frac{\eta}{1-a_{2}} .
$$

A second relation of this type will be obtained by interchanging the role of $T_{1}$ and $T_{2}$. Hence, the conclusion follows by the properties of the functional $H$.

Competing interests

The authors declare that they have no competing interests.

Authors' contributions

Both authors made equal contribution to this article regarding results, conception and drafting the manuscript. The authors read and approved the final manuscript.

\section{Author details}

'Department of Business, Babeş-Bolyai University Cluj-Napoca, Horea street, 7, Cluj-Napoca, 400174, Romania.

${ }^{2}$ Department of Mathematics, Babeş-Bolyai University Cluj-Napoca, Kogalniceanu street, 1, Cluj-Napoca, 400084, Romania.

\section{Acknowledgements}

The work of the second author is supported by financial support of a grant of the Romanian National Authority for Scientific Research, CNCS-UEFISCDI, project number PN-II-ID-PCE-2011-3-0094.

Received: 15 October 2013 Accepted: 13 January 2014 Published: 17 Feb 2014

\section{References}

1. Jachymski, J: The contraction principle for mappings on a metric space with a graph. Proc. Am. Math. Soc. 136, 1359-1373 (2008)

2. Gwóźdź-Lukawska, G, Jachymski, J: IFS on a metric space with a graph structure and extensions of the Kelisky-Rivlin theorem. J. Math. Anal. Appl. 356, 453-463 (2009)

3. Nicolae, A, O'Regan, D, Petrușel, A: Fixed point theorems for single-valued and multivalued generalized contractions in metric spaces endowed with a graph. Georgian Math. J. 18, 307-327 (2011)

4. Beg, I, Butt, AR, Radojevic, S: The contraction principles for set-valued mappings on a metric space with a graph. Comput. Math. Appl. 60, 1214-1219 (2010)

5. Dinevari, T, Frigon, M: Fixed point results for multivalued contractions on a metric space with a graph. J. Math. Anal Appl. 405, 507-517 (2013)

6. Border, K: Fixed Point Theorems with Applications to Economic and Game Theory. Cambridge University Press, London (1985)

7. Yuan, GX-Z: KKM Theory and Applications in Nonlinear Analysis. Dekker, New York (1999)

8. Harjani, J, Sadarangani, K: Fixed point theorems for weakly contractive mappings in partially ordered sets. Nonlinear Anal. 71, 3403-3410 (2009)

9. Nieto, JJ, Rodríguez-López, R: Contractive mapping theorems in partially ordered sets and applications to ordinary differential equations. Order 22, 223-239 (2005) 
10. Nieto, JJ, Rodríguez-López, R: Existence and uniqueness of fixed points in partially ordered sets and applications to ordinary differential equations. Acta Math. Sin. Engl. Ser. 23, 2205-2212 (2007)

11. Nieto, JJ, Pouso, RL, Rodríguez-López, R: Fixed point theorems in ordered abstract spaces. Proc. Am. Math. Soc. 135, 2505-2517 (2007)

12. O'Regan, D, Petruşel, A: Fixed point theorems in ordered metric spaces. J. Math. Anal. Appl. 341, 1241-1252 (2008)

13. Petrușel, A, Rus, IA: Fixed point theorems in ordered L-spaces. Proc. Am. Math. Soc. 134, 411-418 (2006)

14. Ran, ACM, Reurings, MC: A fixed point theorem in partially ordered sets and some applications to matrix equations. Proc. Am. Math. Soc. 132, 1435-1443 (2004)

15. Rus, IA: Generalized Contractions and Applications. Transilvania Press, Cluj-Napoca (2001)

16. Chifu, C, Petruşel, G, Bota, M: Fixed points and strict fixed points for multivalued contractions of Reich type on metric spaces endowed with a graph. Fixed Point Theory Appl. 2013, 203 (2013). doi:10.1186/1687-1812-2013-203

17. Ćirić, LB: A generalization of Banach's contraction principle. Proc. Am. Math. Soc. 45, 267-273 (1974)

18. Petruşel, A, Rus, IA: Well-posedness of the fixed point problem for multivalued operators. In: Carja, O, Vrabie, II (eds.) Applied Analysis and Differential Equations, pp. 295-306. World Scientific, Hackensack (2007)

19. Petruşel, A, Rus, IA, Yao, J-C: Well-posedness in the generalized sense of the fixed point problems for multivalued operators. Taiwan. J. Math. 11, 903-914 (2007)

10.1186/1029-242X-2014-77

Cite this article as: Chifu and Petruşel: Ciric-type $\delta$-contractions in metric spaces endowed with a graph. Journal of Inequalities and Applications 2014, 2014:77

\section{Submit your manuscript to a SpringerOpen ${ }^{\circ}$ journal and benefit from:}

- Convenient online submission

Rigorous peer review

- Immediate publication on acceptance

- Open access: articles freely available online

- High visibility within the field

- Retaining the copyright to your article 